Www.jmscr.igmpublication.org Impact Factor 5.84

Index Copernicus Value: 83.27

ISSN (e)-2347-176x ISSN (p) 2455-0450

crossref DOI: _https://dx.doi.org/10.18535/jmscr/v5i8.114

\title{
Factors associated with mortality outcomes in neonatal septicemia in Srinagarind hospital, Thailand
}

\section{Authors \\ Zarghoon Tareen $^{1}$, Junya Jirapradittha ${ }^{2}$, Chukiat Sirivichayakul ${ }^{3}$, Watcharee Chokejindachai ${ }^{4}$}

${ }^{1}$ Department of Tropical Pediatrics, Faculty of Tropical Medicine, Mahidol University, Thailand and

Department of Pediatrics, Faculty of Medicine, Kandahar University, Afghanistan

Email: zarghoon_tareen@yahoo.com, Mobile:0093(0)700363511

${ }^{2}$ Assoc. Prof., Department of Pediatrics, Faculty of Medicine, Khon Kaen University, Thailand

Email:jjunya@yahoo.com

${ }^{3}$ Assoc. Prof., Dept of Tropical Pediatrics, Faculty of Tropical Medicine, Mahidol University, Thailand

Email: chukiat.sir@mahidol.ac.th

${ }^{4}$ Assist. Prof., Dept of Tropical Pediatrics, Faculty of Tropical Medicine, Mahidol University, Thailand

Email: watcharee.cho@mahidol.ac.th

\begin{abstract}
ABSTRUCT
Background: Neonatal Septicemia is a major cause of mortality and morbidity in newborns both in developed and developing countries.

Objective: The objective of this study was to determine the risk factors for mortality in neonatal septicemia.

Materials and Methods: This retrospective case-control study was conducted in Srinagarind Hospital, Khon Kaen, Thailand. The study considered the demographics, laboratory results, and clinical features for a total of 133 patients during the period May 2005-September 2010. Thirty four out of these patients died from their condition.

Results: Investigation of neonatal demographics found that low Apgar scores in 1 minute (OR 12.237, P<0.001) and 5 min (OR 13.143, $P<0.001)$, VLBW (OR 5.312, P 0.001), EOS (3.749, P 0.001), prematurity (2.723, $P$ 0.01), and out born delivery $(6.253, P<0.001)$, were all significantly associated with fatality. Laboratory results showed that hyperglycemia (OR 6.213, P 0.001) and thrombocytopenia (3.853, P 0.002), were significant contributors to fatality. Among all clinical features, lethargy (14.667, $P<0.001)$, apnea (OR 13.160, P<0.001), poor feeding (OR 7.807,P<0.001), hypothermia (OR 4.807, P <0.001) and jaundice (OR4.769< P0.007), were significantly associated with fatality. Gram-negative bacteria were frequently isolated from dead septicemic neonates. E. coli was the most common bacteria isolated from dead septicemic neonates (18.2\%), followed by Klebsiella spp. (15.9\%), Enterobacter spp. (15.9\%), Acinetobacter spp. (13.6\%) and Pseudomonas spp. (11.3\%).

Conclusion: Early detection and management of these associated factors are necessary to prevent severe and life threatening complications and death in neonatal septicemia. Strict infection control measures remain the mainstay in the management of the multidrug resistant bacterial infections in neonates.

Keywords: Mortality outcomes, Neonatal septicemia, Srinagarind Hospital, Thailand.
\end{abstract}

\section{Introduction}

Over 130 million babies are born every year. Four million newborns, worldwide die within their 28 days of life, and over 3 million newborns die in first week after birth ${ }^{[1]}$. Neonatal Septicemia is a major cause of mortality and morbidity in newborns both in developed and developing countries ${ }^{[2] .}$ It is responsible for $30-50 \%$ of total neonatal death in developing countries ${ }^{[3]}$. Despite advances in neonatal care, overall case fatality 
rates from septicemia range from $2 \%$ to as high as $50 \%{ }^{[4]}$. Infection cause 1.6 million infants death in developing countries each year ${ }^{[1]}$. Up to $50 \%$ of neonatal intensive care unit (NICU) patients experience one or more episodes of septicemia, which is associated with an increased risk of long term sequelae ${ }^{[5]}$.

The frequency of death is significantly higher in preterm babies. Low birth weight, IUGR,. Also highest mortality is associated with blood culture positive for gram negative bacteria and Staphylococcus aureus ${ }^{[6]}$.

\section{Materials and Methods}

Study design: This was a retrospective case control study. Data were compiled from microbiology laboratory and medical record. The study was conducted from October 2010 to March 2011 in Srinagarind Hospital, Faculty of Medicine, Khon Kaen University, located in Khon Kaen province in northeast Thailand.

Data source: Microbiology data and Medical record of neonatal patients in Srinagarind Hospital from May 2005 to September 2010

\section{Inclusion criteria}

1. Age equal or less than 28 days at the onset of illness.

2. The blood culture is positive for bacteria.

3. The medical records are available.

\section{Exclusion criteria}

1. The culture result is positive only for fungus.

2. The medical record is not available.

Sample size calculation: Sample size calculation: Sample size calculation was performed using Epi info 6 version 3.5.1. The estimated sample sizes are 34 for case and 99 for control group. The ratio of case and control from is 1:3. Total estimated study group of neonatal septicemia are 133 neonates.

Data analysis: Analyses were calculated using a 2-tailed p-value $<0.05$ as statistically significant cut off point. The clinical data was described using descriptive statistics such as mean \pm SD or median with range for continuous variable, and frequency distribution, proportion, rate and ratio, and percentage for categorical variables. The differences in clinical features and laboratory findings of neonatal septicemia between fatal and survival outcome were compared using odds ratio and Chi-square test or Fischer-exact test for categorical variables and student's t-test or Mann Whitney $U$ test or one way ANOVA test for continuous variable as appropriate. SPSS 15 statistical software was used for all calculations. P-value of less than 0.05 was considered statistically significant, P-value $<0.01$ as highly significant and $\mathrm{P}$-value $<0.001$ was extremely significant.

Study procedure: Data collection: The list of the neonatal septicemia patients with positive hemoculture were retrieved from microbiological records in laboratory. The patient's medical records were then collected from hospital registry, and then check for the inclusion criteria. The medical records from eligible patients were reviewed, and information was transferred to the case record form. The neonatal septicemia patients with positive blood culture who died were assigned as the case group, whereas the neonatal septicemia patients with positive blood culture who survived were the control group.

Data Management: After all raw data were transferred; data cleaning process was done. Illogical numbers (no data, negative number and blank item) were rechecked. The original medical record was explored again if necessary. Then some variables were added based on the raw data.

Ethical committee approval: Ethical approval of this study was obtained from 2 ethical committees, the Faculty of Tropical Medicine, Mahidol University, and Faculty of Medicine Khon Kaen University, both in November 2010.

\section{Result}

\section{Medical records searching}

During the study, 285 neonates with positive blood culture from May 2005 to September 2010 were found from microbiology laboratory data, among them 50 were died and 235 were survived. In dead neonates 34 met the inclusion criteria and included in the study. Sixteen were excluded. 
From 235 survived patients, 99 were selected searching is shown in Figure 1.1. randomly. The diagram of the medical records

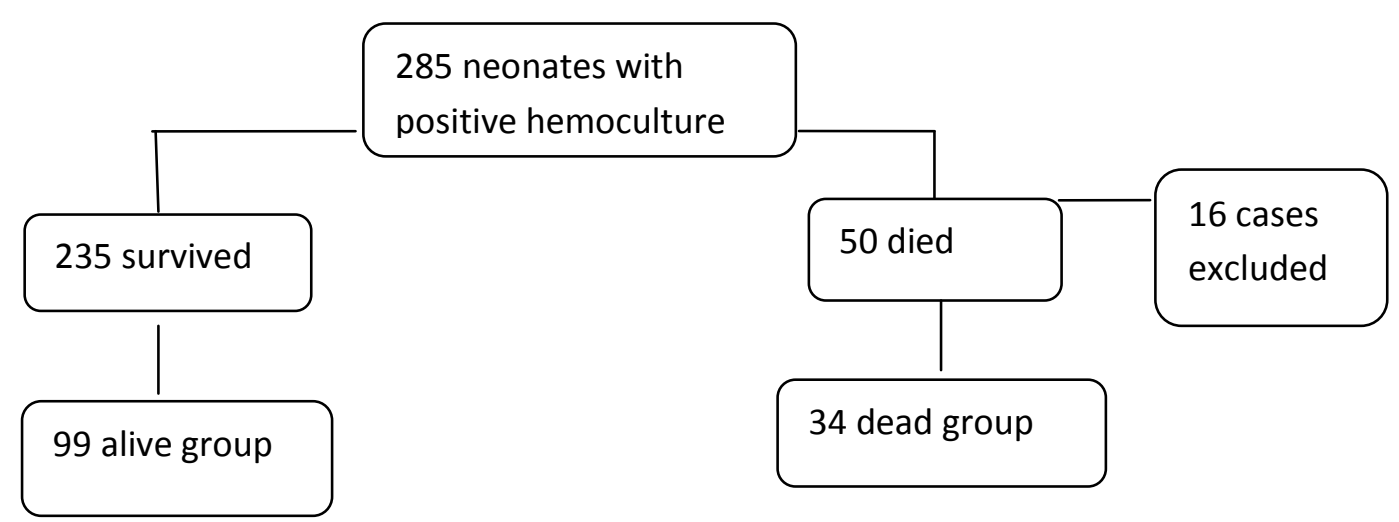

Figure1: The medical records searching process

Regarding patients demographic data, early onset septicemia [19 (55.9\%)] (Odds Ratio 3.749, P 0.001 ), very low birth weight (VLBW)[17 (50.0)] (OR 5.312, P0.001), preterm delivery [23 $(67.7 \%)$ ] (OR 2.723, P0.01), Out born neonates [24 (70.9\%)] (OR 6.253, P <0.001) low Apgar score (0-3) at first minute [15, (44.1\%)] (OR 12.237, $\mathrm{P}<0.001)$ and 5 minute $(\leq 6)[17(50.0 \%)]$, (OR 13.143, $\mathrm{P}<0.001$ ), has significant association with fatality. The demographic data has shown in table 1 .

Table 1: Demographic risk factors for fatality in neonatal septicemia

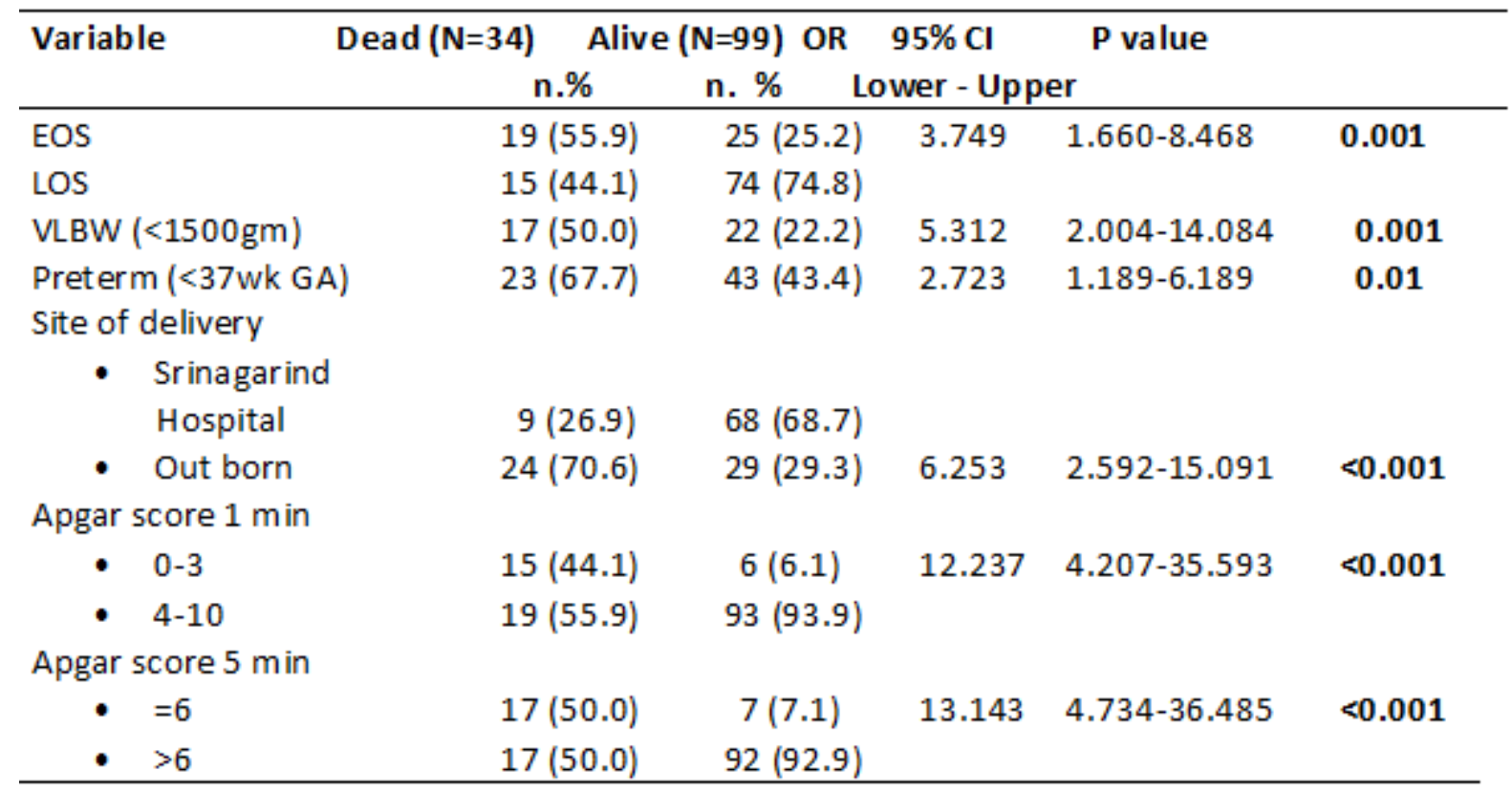

Regarding the neonates clinical data, Lethargy [22 (64.7\%)] (OR 14.667, P <0.001),Apnea [14 (41.2\%) (OR 13.160 $\mathrm{P}<0.001)$, Poor feeding [15 (44.1\%)] (OR 7.807, P<0.001), Hypothermia [23 $(67.7 \%)$ (4.807, $\mathrm{P}<0.001)$, and Jaundice [7 (20.6\%)] (OR4.769, P 0.007), has significantly association with mortality outcome table 2 . 
Table 2: Clinical risk factors for fatality in neonatal septicemia

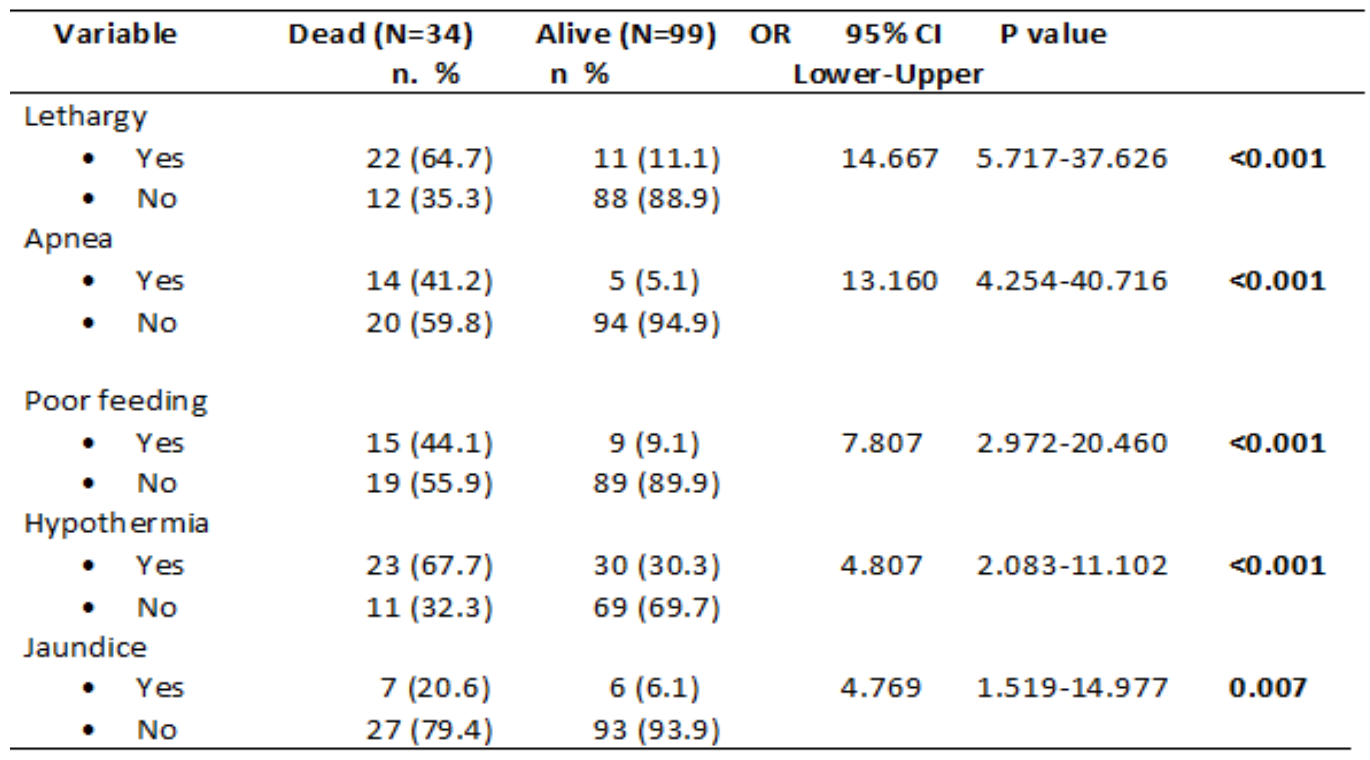

The results of blood glucose and platelet counts are presented in table 3.In our study, Hyperglycemia [11 (32.4\%)](OR 6.213, P 0.001) and Thrombocytopenia [18 (52.9\%)] (OR 3.853, P $0.002)$ have association with fatality in neonatal septicemia.

Table 3: Laboratory risk factors for fatality in neonatal septicemia

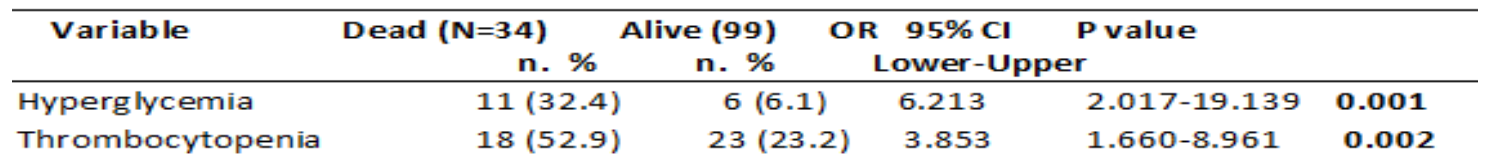

Regarding causative organisms, it was found that gram negative bacteria were isolated more frequently from death neonates. In this study E.coliwas the commonest bacteria isolated from dead neonates (18\%) followed by klebsella spp
(15.9\%), enterobacter $\operatorname{spp}(15.9 \%)$, acinetobacter spp $(13.6 \%)$ and pseudomonas $\operatorname{spp}(11.3 \%)$. Gram positive bacteria were frequently isolated from survive neonates compare to dead septicemic neonates. Table 4.

Table 4: Isolates blood cultured from neonates with septicemia by outcome

\begin{tabular}{|c|c|c|}
\hline Organism & $\begin{array}{l}\text { Dead } \\
\text { n. \% }\end{array}$ & $\begin{array}{l}\text { Alive } \\
\text { n. \% }\end{array}$ \\
\hline \multicolumn{3}{|l|}{ Gram negative } \\
\hline $\begin{array}{l}\text { - Escherichia coli } \\
\text { - Klebsiella spp. } \\
\text { - Enterobacter spp. } \\
\text { - Acinetobacter spp } \\
\text { - Pseudomonas spp. }\end{array}$ & $\begin{array}{l}8(18.2) \\
7(15.9) \\
7(15,9) \\
6(13.6) \\
5(11.3) \\
0(0.0)\end{array}$ & $\begin{aligned} 3 & (3.0) \\
11 & (11.1) \\
1 & (1.0) \\
7 & (7.1) \\
3 & (3.0) \\
1 & (1.0)\end{aligned}$ \\
\hline \multicolumn{3}{|l|}{ Gram positive } \\
\hline $\begin{array}{l}\text { - Staphylococcus aureus } \\
\text { - Enterococci spp. } \\
\text { - Goagolase negative Staphylococcus } \\
\text { - Streup B streptococci } \\
\text { - Stroccus virdan }\end{array}$ & $\begin{array}{l}3(6.8) \\
3(6.8) \\
2(4.5) \\
2(4.5) \\
1(2.7)\end{array}$ & $\begin{array}{l}14(14.1) \\
21(21.2) \\
18(18.2) \\
9(9.1) \\
11(11.2)\end{array}$ \\
\hline Total & & \\
\hline
\end{tabular}




\section{Discussion}

Neonatal Septicemia is a major cause of mortality and morbidity in newborns both in developed and developing countries ${ }^{[2]}$. It is responsible for 30 $50 \%$ of total neonatal death in developing countries ${ }^{[3]}$. We have used a case control approach to identify the risk factors for mortality outcome in neonatal septicemia.

As shown in this study, the number of EOS was higher in dead patients so, it was the significant risk factor for mortality. The same result was reported from many countries ${ }^{[6,7]}$. the frequency of VLBW (<1500gm) was higher in dead $(50.0 \%)$ compared to survived neonates $(22.2 \%)$, it was the potential risk factor for neonatal death. As well as the frequency of preterm delivery ( $<37$ weeks gestation) was also higher in dead compared to survived neonates. It was a significant risk factor among dead neonates. Premature and low birth weight infants are at increased risk for developing complications of septicemia because of deficiencies in humoral and cellular immunity ${ }^{[8,}$ 9]. Similar were the observations of different workers, who reported significant risk in prematurity and low birth weight ${ }^{[6,}$ 10]. In this study, when we compared Apgar score at $1 \mathrm{~min}$ between two groups, there were statistically higher proportion of low Apgar score (0-3) in dead neonates than survived patients. Similarly, when comparing Apgar score at 5 minutes, dead neonates more frequently had Apgar score of $\leq 6$.A study from Denmark reported the same results $^{[11]}$. In this study among the clinical signs and symptoms, apnea, lethargy, and poor feeding, jaundice were statistically significant associated with dead in neonatal septicemia patients. The same result was reported from Tanzania ${ }^{[12]}$.Regarding laboratory parameters, thrombocytopenia had statistically significant association with mortality outcome in this study. Most of the studies documented the association of thrombocytopenia with gram negative bacterial septicemia ${ }^{[13,14]}$.A study from Iran reported the association of thrombocytopenia and mortality from neonatal septicemia ${ }^{[15]}$. Hyperglycemia is a risk factor for early mortality in preterm neonates.
In this study we have found the statistically significant association between hyperglycemia and neonatal mortality from neonatal septicemia. A study from Netherland similarly has found the association of hyperglycemia and mortality from neonatal septicemia and other comorbidities ${ }^{[16]}$. A study from United States reported the relation of hyperglycemia and mortality from septicemia in low birth weight neonates ${ }^{[17]}$.In this study, It was found that gram negative bacteria were isolated more frequently from dead neonates than from survived neonates. Many study reported the same result $^{[6,}{ }^{12]}$.In this study among gram negative microorganisms, E.coli was the commonest bacteria isolated from dead neonates (18\%) followed by klebsella spp (15.9\%), enterobacter spp (15.9\%), acinetobacter spp (13.6\%) and pseudomonas $\operatorname{spp}(11.3 \%)$. The same result was observed in a study from Tanzania, which reported high mortality rate with $E$. coli neonatal septicemia followed by Klebsiella spp $^{[18] \text {. }}$

\section{Conclusion}

Neonatal septicemia is a major cause of morbidity and mortality among children in both developed and developing countries.

Investigation of neonatal demographics found that low Apgar scores in 1 minute and $5 \mathrm{~min}$, VLBW, EOS, prematurity, and out born delivery, were all significantly associated with fatality. Laboratory results showed that hyperglycemia and thrombocytopenia, were significant contributors to fatality. Among all clinical features, lethargy, apnea, poor feeding, hypothermia, and jaundice were significantly associated with fatality. Gramnegative bacteria were frequently isolated from dead septicemic neonates. E. coli was the most common bacteria isolated from dead septicemic neonates, followed by Klebsiella spp., Enterobacter spp., Acinetobacter spp., and Pseudomonas spp.

Early detection and management of these associated factors are necessary to prevent severe and life threatening complications and death in neonatal septicemia. Strict infection control measures remain the mainstay in the management 
of the multidrug resistant bacterial infections in neonates.

\section{Acknowledgments}

We are grateful to Kandahar University, Afghanistan Ministry of Higher Education, and World Bank. My special thanks for my co advisor in Srinagarind Hospital, Asst Prof. Junya Jirapradittha, for her valuable comments, guidance, and kindness during my data collection and thesis writing.

\section{References}

1. Lander T. Neonatal and perinatal mortality: country, regional and global estimates. World Health Organization; 2006.

2. Jain NK, Jain VM, Maheshwari S. Clinical profile of neonatal sepsis. Kathmandu Univ Med J (KUMJ). 2003;1(2):117-20.

3. Sankar MJ, Agarwal R, Deorari AK, Paul VK. Sepsis in the newborn. Indian $J$ Pediatr. 2008;75(3):261-6.

4. Klein JO. Bacterial sepsis and meningitis. In: Remington JS, Klein JO, eds. Infectious diseases of the fetus and newborn infant. 5th ed. Philadelphia: WB Saunders, 2001; p. 943-98.

5. Gray JW. Which Factors Predict HospitalAcquired Late-onset Neonatal Sepsis? Pediatr Health. 2008;2:477-84.

6. Jumah DS, Hassan MH. Predictors of mortality outcome in neonatal sepsis. The Med J of BasrahUniversity. 2007;25(1): 11-8.

7. Jiang JH, Chiu NC, Huang FY, Kao HA, Hsu CH, Hung HY, Chang JH, Peng CC. Neonatal sepsis in the neonatal intensive care unit: characteristics of early versus late onset. Journal of microbiology, immunology, and infection $=$ Wei mian yu gan ran za zhi. 2004 Oct;37(5):301-6.

8. Fanaroff AA, Korones SB, Wright LL, Verter J, Poland RL, Bauer CR, et al. Incidence, presenting features, risk factors and significance of late onset septicemia in very low birth weight infants. The
National Institute of Child Health and Human Development Neonatal Research Network. Pediatr Infect Dis J. 1998;17(7):593-8.

9. Shah GS, Budhathoki S, Das BK, Mandal $\mathrm{RN}$. Risk factors in early neonatal sepsis. Kathmandu Univ Med J (KUMJ). 2006;4(2):187-91.

10. Stoll BJ, Hansen NI, Higgins RD, Fanaroff AA, Duara S, Goldberg R, et al. Very low birth weight preterm infants with early onset neonatal sepsis: the predominance of gram-negative infections continues in the National Institute of Child Health and Human Development Neonatal Research Network, 2002-2003. Pediatr Infect Dis J. 2005;24(7):635-9.

11. Ehrenstein V. Association of Apgar scores with death and neurologic disability. Clin Epidemiol. 2009;1:45-53.

12. Kayange N, Kamugisha E, Mwizamholya DL, Jeremiah S, Mshana SE. Predictors of positive blood culture and deaths among neonates with suspected neonatal sepsis in a tertiary hospital, Mwanza-Tanzania. BMC Pediatr. 2010;10:39.

13. Shyamala KV, Subbalakshmi NK, Raghuverra K. Role of platelet count and CRP level in Gram negative versus Gram positive bacterial sepsis in low birth weight neonates. Chinese clinical medicine J. 2010;5(8):474-79

14. Guida JD, Kunig AM, Leef KH, McKenzie SE, Paul DA. Platelet count and sepsis in very low birth weight neonates: is there an organism-specific response? Pediatrics. 2003;111(6 Pt 1):1411-5.

15. Torkaman M, Afsharpaiman SH, Hoseini MJ, Moradi M, Mazraati A, Amirsalari S, et al. Platelet count and neonatal sepsis: a high prevalence of Enterobacter spp. Singapore Med J. 2009;50(5):482-5.

16. Van der Lugt NM, Smits-Wintjens VE, van Zwieten $\mathrm{PH}$, Walther FJ. Short and long term outcome of neonatal hyperglycemia in very preterm infants: a 
retrospective follow-up study. BMC Pediatr. 2010;10:52.

17. Kao LS, Morris BH, Lally KP, Stewart CD, Huseby V, Kennedy KA. Hyperglycemia and morbidity and mortality in extremely low birth weight infants. J Perinatol. 2006;26(12):730-6.

18. Blomberg B, Jureen R, Manji KP, Tamim BS, Mwakagile DS, Urassa WK, et al. High rate of fatal cases of pediatric septicemia caused by gram-negative bacteria with extended-spectrum betalactamases in Dar es Salaam, Tanzania. J Clin Microbiol. 2005;43(2):745-9. 